\title{
FAKTOR-FAKTOR YANG MEMENGARUHI KEPUTUSAN KONSUMEN MELAKUKAN PEMBELIAN MAKANAN MELALUI MEDIA SOSIAL
} Aylinna Ongsano

Universitas Ciputra Surabaya

Email: ay_ongsano@yahoo.com

Michael Ricky Sondak

Universitas Ciputra Surabaya

Email:michael@ciputra.ac.id

\begin{abstract}
Sophistication of technology is now increasingly, people becomes easier to access any information just by using internet. This evolution is called globalization. Now globalization makes Indonesian people tend to likes instant and practical things. Internet users in Indonesia is now increasing and most are social media active users. This makes Indonesia have a good prospects to do online business. The purpose of this study is to find out the factors that influence consumer's decision for purchase online food and to determine the most dominant factor in consumer's decision for purchasing online food. Population in this research is all Indonesia people who already experienced online transaction. Meanwhile, sample of this research is 73 consumers who have already purchased online food. Moreover, the technique of data collection in this study is through questionnaires distribution method and the questionnaires is using Likert scale instrument. Furthermore, the researcher process the data using SPSS with Exploratory Factor Analysis to obtain significant conclusions based on these research. Based on the hypothesis that has been calculated using the SPSS, the results are there are five factors that influence consumer's decision for purchasing food through social media and the most dominant factor is life style, because it has the most high eigen value.
\end{abstract}

Keywords: Globalization, Social Media, Online Business, Exploratory Factor Analysis

\section{ABSTRAK}

Kecanggihan teknologi saat ini sudah semakin modern, masyarakat menjadi lebih mudah untuk mengakses informasi yang ada di dunia hanya dengan menggunakan internet. Perkembangan zaman ini biasa disebut globalisasi. Globalisasi membuat masyarakat Indonesia sekarang cenderung lebih menyukai hal-hal yang instan dan praktis. Pengguna internet di Indonesia semakin meningkat dan sebagian besar merupakan pengguna aktif media sosial. Hal ini membuat Indonesia mempunyai prospek yang baik untuk melakukan bisnis online. Tujuan dari penelitian ini yaitu untuk mengetahui apa saja faktor-faktor yang mempengaruhi keputusan konsumen melakukan pembelian makanan secara online dan mengetahui faktor yang paling dominan dalam keputusan konsumen melakukan pembelian makanan secara online. Populasi yang diterapkan dalam penelitian ini yaitu seluruh masyarakat Indonesia yang pernah melakukan transaksi online, sedangkan sampel yang diteliti adalah 73 konsumen yang pernah melakukan transaksi pembelian makanan secara online. Teknik pengumpulan data dalam penelitian ini dilakukan dengan membagikan kuesioner yang menggunakan instrumen skala Likert. Selanjutnya, peneliti mengolah data hasil penelitian menggunakan SPSS dengan uji analisis faktor. Setelah melakukan uji analisis faktor hasil yang didapatkan adalah terdapat lima faktor yang menjadi pengaruh konsumen melakukan pembelian makanan melalui media sosial dan faktor yang paling dominan adalah faktor gaya hidup karena memiliki nilai eigen yang paling tinggi.

Kata Kunci: Globalisasi, Media Sosial, Bisnis Online, Analisis Faktor. 


\section{PENDAHULUAN}

Saat ini perkembangan zaman sudah sangat pesat. Dengan kecanggihan teknologi yang semakin modern, masyarakat dipermudah mengakses seluruh informasi yang ada di dunia hanya dengan menggunakan internet. Perkembangan zaman ini biasa disebut dengan globalisasi. Globalisasi membuat pengaruh yang besar termasuk dalam hal gaya hidup. Tidak hanya di beberapa negara saja yang mengalami globalisasi, namun di Indonesia juga tidak terkecuali, pengguna internet di Indonesia mencapai sepertiga lebih dari jumlah total populasi yang ada di Indonesia itu hampir 90\% adalah pengguna aktif media sosial. Indonesia memiliki prospek yang sangat baik untuk melakukan bisnis online karena jumlah penduduk yang menggunakan media sosial dan data pengguna internet yang setiap tahun meningkat. Peluang yang ada untuk membuka bisnis online sangatlah bagus, karena perkembangan teknologi dan informasi yang sudah tersedia sekarang, membuat semakin mudah dan cepat untuk mempromosikan usaha yang ingin dibuka.

\section{TINJAUAN PUSTAKA}

\section{Bisnis Makanan}

Bertambah banyaknya bisnis makanan yang ada sekarang memiliki alasan yang kuat. Budi (2015:9) mengatakan bisnis makanan secara kalkulasi memang bisnis yang tidak ada matinya. Semua orang butuh makan dan pemahaman seperti itu yang selalu ada pikiran masyarakat. Secara fakta hal itu benar, pasarnya besar dan terus menerus membesar seiring pertumbuhan jumlah manusia. Karena alasan tersebut, maka banyak para pebisnis yang tertarik ingin membuka bisnis makanan.

\section{E-commerce}

E-commerce dapat dipahami sebagai kegiatan transaksi perdagangan baik barang dan jasa melalui media elektronik yang memberikan kemudahan di dalam kegiatan bertransaksi konsumen di internet (Ritonga, 2015)

\section{Perilaku Konsumen}

Menurut Schiffman dan Kanuk (2010:23) mengatakan bahwa dalam penelitian selanjutnya mengungkapkan bahwa konsumen akan membeli barang tanpa berpikir panjang dan akan mudah terpengaruh. Tidak hanya terpengaruh dari keluarga, teman, iklan dan panutan saja, tapi juga terpengaruh dengan suasana hati, keadaan, dan emosi. Dan banyak faktor yang dapat mempengaruhi perilaku konsumen dalam mencapai keputusan pembelian, bisa faktor eksternal ataupun faktor internal.

Menurut Suryani (2013) ada tiga faktor yang perlu di perhatikan dalam mempelajari perilaku konsumen yang dapat mempengaruhi pengambilan keputusan. Berikut adalah faktorfaktornya:

1) Faktor internal seperti persepsi, motivasi, pembelajaran, sikap, kepribadian, dan gaya hidup akan berpengaruh terhadap preferensi produk dan merek dalam pengambilan keputusan konsumen.

2) Pengaruh sosial seperti budaya, $s u b$ budaya, kelas sosial, dan keanggotaan kelompok.

Faktor situasional seperti lingkungan fisik dan waktu meskipun faktor situsional ini susah 
3) dikendalikan oleh pemasar, tetapi jika faktor situsional ini dapat dipahami oleh pemasar, maka akan sangat berguna dalam mempengaruhi konsumen

\section{METODE PENELITIAN}

Peneliti menggunakan metode kuantitatif dalam penelitian ini karena ingin mengetahui informasi dari populasi yang luas, tapi tidak mendalam dan juga ingin mengetahui pengaruh perlakuan tertentu terhadap yang lain. Pada penelitian ini, populasi yang peneliti ambil adalah infinite population. Sampel penelitian ini adalah konsumen yang pernah melakukan transaksi pembelian makanan secara online. Penelitian ini menggunakan non probability sampling. Non probability sampling mempunyai banyak macam jenis, dan pada penelitian ini memakai teknik penarikan sampel insidental. Menurut Sugiyono (2015:124), sampling insidental adalah teknik penentuan sampel berdasarkan kebetulan, yaitu siapa saja yang secara kebetulan atau insidental bertemu dengan peneliti yang sesuai dengan kriteria dapat digunakan sebagai sampel, bila dipandang orang yang kebetulan ditemui itu cocok sebagai sumber data. Pada penelitian ini terdapat dua jenis data yang digunakan yaitu data primer dan data sekunder. Data primer di dapat dari responden secara langsung. Data sekunder di dapat dari sumber yang tidak langsung seperti teori-teori atau penelitian terdahulu.

Penelitian ini menggunakan kuesioner dengan pengukuran skala Likert sebagai metode dalam pengumpulan datanya. Terdapat dua macam, kuesioner online (melalui google form) dan offline (dicetak di kertas). Setelah mendapatkan instrumen penelitian, peneliti melakukan uji validitas dan reliabilitas untuk mengetahui kelayakan dari variabel tersebut. Teknik analisis penelitian ini menggunakan analisis faktor atau exploratory factor analysis. Ada lima tahapan dalam melakukan analisis faktor menurut Murwani (2009:2) dalam Tirtana (2013:26) yaitu persiapan data, ekstraksi faktor, rotasi sumbu faktor, pengoperasian model, dan penggunaan hasil

\section{HASIL DAN PEMBAHASAN Deskriptif Data Responden}

Profil responden berdasarkan jenis kelamin dari kuesioner online dan offline adalah 45 responden wanita sedangkan responden pria hanya 28. Dari sini dapat disimpulkan bahwa wanita lebih banyak menggunakan media sosial dan lebih sering membeli makanan secara online dari pada pria. Profil responden berdasarkan usia dari kuesioner online dan offline adalah yang sering menggunakan media sosial adalah yang berusia 18-25 tahun.

\section{Deskriptif Variabel Penelitian}

Hasil jawaban kuesioner variabel X1 hingga X19 yang menunjukkan ratarata setuju ada sepuluh dan yang menunjukkan rata-rata netral ada tujuh. Responden lebih banyak yang setuju dari variabel-variabel yang ada dan meskipun netral, namun netral yang cenderung dengan pernyataan setuju pada kuesioner yang dibuat oleh peneliti dan membuktikkan bahwa variabel yang diajukan benar dan sesuai dengan pendapat responden.

Peneliti menggunakan analisis faktor melalui SPSS untuk mengolah data, dengan tahap perhitungan :Kaiser-MeyerOlkin (KMO) and Bertlett's Test of Sphericity 
Tabel $1 \mathrm{KMO}$ and Bertlett's Test

\begin{tabular}{|l|l|}
\hline \multicolumn{2}{|l|}{ KMO and Barlett's Test } \\
\hline $\begin{array}{l}\text { Kaiser-Meyer-Olkin Measure of } \\
\text { Sampling }\end{array}$ & 0,658 \\
\hline $\begin{array}{l}\text { Barlett's Test of Sphericity } \\
\text { (Approx. Chi-Square) }\end{array}$ & 398,653 \\
\hline Barlett's Test of Sphericity (df) & 136 \\
\hline Barlett's Test of Sphericity (Sig.) & 0,000 \\
\hline
\end{tabular}

Sampel dikatakan layak untuk digunakan dalam analisis faktor apabila hasil nilai KMO dan Bertlett's Test of Sphericity di atas 0,5 dan hasilnya menunjukkan nilai 0,658 . Maka sampel ini layak sehingga analisis faktor dapat dilanjutkan. Bertlett's Test of Sphericity digunakan untuk menguji variabelvariabel tidak berkorelasi dalam satu populasi. Dari uji ini didapatkan sebesar 398,653 dengan probabilitas kesalahan (tingkat signifikan: 0,000), jadi tidak ada korelasi antar variabel sehingga analisis faktor dapat dilakukan.

\section{2) Anti Image Correlation}

Pada perhitungan analisis faktor ini peneliti memasukkan 17 variabel karena ke 17 variabel tersebut telah dinyatakan valid. Syarat agar berhasil melakukan uji MSA adalah hasil perhitungan Anti Image Correlation menghasilkan angka MSA lebih baik dan di atas 0,5. Karena ada beberapa variabel pada uji MSA yang menghasilkan nilai di bawah 0,5 peneliti melakukan beberapa kali test untuk menghasilkan nilai yang sesuai dengan standar.3) Communalities

Dalam communalities, menunjukkan besarnya nilai korelasi dengan faktor yang terbentuk. X15 memiliki nilai ekstrasi paling tinggi yaitu 0,836 yang berarti nilai ekstraksi ini merupakan nilai yang paling kuat dengan faktor yang terbentuk 
Tabel 2 Communalities.Indikator

\begin{tabular}{|l|l|l|}
\hline & Initial & Extraction \\
\hline $\mathrm{X} 5$ & 1,000 & 0,746 \\
\hline $\mathrm{X} 6$ & 1,000 & 0,792 \\
\hline $\mathrm{X} 7$ & 1,000 & 0,614 \\
\hline $\mathrm{X} 8$ & 1,000 & 0,654 \\
\hline $\mathrm{X} 9$ & 1,000 & 0,577 \\
\hline $\mathrm{X} 10$ & 1,000 & 0,687 \\
\hline $\mathrm{X} 11$ & 1,000 & 0,606 \\
\hline $\mathrm{X} 12$ & 1,000 & 0,785 \\
\hline $\mathrm{X} 13$ & 1,000 & 0,660 \\
\hline $\mathrm{X} 14$ & 1,000 & 0,773 \\
\hline $\mathrm{X} 15$ & $\mathbf{1 , 0 0 0}$ & $\mathbf{0 , 8 3 6}$ \\
\hline $\mathrm{X} 16$ & 1,000 & 0,650 \\
\hline $\mathrm{X} 17$ & 1,000 & 0,526 \\
\hline $\mathrm{X} 19$ & 1,000 & 0,756 \\
\hline
\end{tabular}

4) Eigenvalue dan Total Variance Explained

Sebagai ringkasan informasi yang terkandung dalam variabel asal, sejumlah faktor wajib disaring dan ditentukan oleh nilai eigen dari faktor tersebut. Dengan menggunakan analisis faktor pada tahap keempat ini menghasilkan lima faktor yang mempengaruhi keputusan konsumen melakukan pembelian makanan secara online karena nilai eigen yang dihasilkan di atas satu

\begin{tabular}{|l|l|l|l|}
\hline Faktor & Nilai Eigen & Varians (\%) & Kumulatif (\%) \\
\hline 1 & 4,105 & 29,323 & 29,323 \\
\hline 2 & 1,675 & 11,967 & 41,290 \\
\hline 3 & 1,426 & 10,185 & 51,475 \\
\hline 4 & 1,280 & 9,141 & 60,615 \\
\hline 5 & 1,178 & 8,411 & 69,026 \\
\hline
\end{tabular}

Hasil akhir dari analisis faktor adalah matrik faktor. Matrik faktor mempunyai koefisien yang dipakai untuk menyatakan variabel standar yang disebut faktor, koefisien faktor loading menjabarkan korelasi antara variabel asal dan faktornya. Nilai korelasi yang besar menyatakan hubungan yang kuat antar variabel dan faktor asal sehingga variabel tersebut dapat digunakan untuk mengartikan faktor. Hasilnya dapat terlihat pada tabel berikut 
Tabel 4 Hasil Rotasi Komponen Matrik

\begin{tabular}{|c|c|c|}
\hline Faktor & Indikator & Faktor Loading \\
\hline F1 & X6 & 0,788 \\
\hline & X15 & 0,767 \\
\hline & X11 & 0,710 \\
\hline & X5 & 0,643 \\
\hline F2 & X12 & 0,848 \\
\hline & X14 & 0,793 \\
\hline & X16 & 0,621 \\
\hline F3 & X19 & 0,836 \\
\hline & X10 & 0,786 \\
\hline F4 & X8 & 0,715 \\
\hline & X9 & 0,665 \\
\hline & X7 & 0,626 \\
\hline F5 & X13 & 0,798 \\
\hline & X17 & 0,535 \\
\hline
\end{tabular}

\section{Hasil Analisis Faktor}

Tabel 5. Hasil Analisis Fakto

\begin{tabular}{|l|l|l|l|}
\hline Faktor & $\begin{array}{l}\text { Nilai } \\
\text { Eigen }\end{array}$ & Variabel Pembentuk Faktor & Nilai Loading \\
\hline Gaya Hidup & 4,105 & $\begin{array}{l}\text { X6 = Tidak mau repot mencari } \\
\text { barang }\end{array}$ & 0,788 \\
\cline { 3 - 4 } & & X15 = Layanan delivery & 0,767 \\
\cline { 3 - 4 } & & X11 = Tidak perlu mengantre & 0,710 \\
\cline { 3 - 4 } & & $\begin{array}{l}\text { X5 = Praktis dan bisa diakses di } \\
\text { mana saja }\end{array}$ & 0,643 \\
\hline \multirow{5}{*}{ Situasional } & 1,675 & X12 = Tidak ada makanan & 0,848 \\
\cline { 3 - 4 } & & X14 = Cuaca buruk & 0,793 \\
\cline { 3 - 4 } & & X16 = Update makanan terbaru & 0,621 \\
\hline Pengaruh Sosial & 1,426 & X19= Alternatif situs lain & 0,836 \\
\cline { 3 - 4 } & & $\begin{array}{l}\text { X10 }=\text { Ingin mencoba produk } \\
\text { baru }\end{array}$ & 0,786 \\
\hline \multirow{3}{*}{ Marketing } & 1,280 & X8 = Harga terjangkau & 0,715 \\
\cline { 3 - 4 } & & X9 = Variasi barang & 0,665 \\
\cline { 3 - 4 } & X7 = Promosi yang menarik & 0,626 \\
\hline Motivasi & 1,178 & X13 = Visualisasi yang bagus & 0,789 \\
\cline { 3 - 4 } & X17 = Jarak tempuh yang jauh & 0,535 \\
\hline
\end{tabular}

Faktor pertama yang dihasilkan pada penelitian adalah faktor gaya hidup. Gaya hidup yang dimaksud adalah gaya hidup masyarakat pada jaman sekarang yang ingin serba praktis. Faktor kedua adalah faktor situasional. Jika penjual dapat memanfaatkan apa saja yang dibutuhkan konsumen pada faktor kedua, 
ini akan mempermudah untuk mendapatkan perhatian dari konsumen. Dan faktor situasional ini pun menjadi salah satu faktor yang mempengaruhi konsumen melakukan pembelian. Setelah faktor situasional ada faktor pengaruh sosial yang menjadi faktor ketiga yang mempengaruhi konsumen melakukan pembelian. Pengaruh sosial sangatlah penting dalam faktor yang mempengaruhi konsumen melakukan pembelian, karena manusia pada dasarnya adalah makhluk sosial, yang tidak bisa hidup tanpa orang lain. Pendapat, masukan, dan saran dari orang lain mempunyai pengaruh yang cukup besar. Apalagi jika orang tersebut mempunyai hubungan yang dekat dengan calon konsumen ini akan menjadi pengaruh sosial yang cukup kuat dalam keputusan konsumen melakukan pembelian. Faktor keempat yang dihasilkan oleh penelitian ini adalah faktor marketing. Belanja online menggunakan teknologi yang berbasis internet, yang lebih mudah dan praktis untuk dijangkau oleh masyarakat, maka untuk melakukan marketing juga lebih mudah. Faktor terakhir adalah faktor motivasi. Motivasi timbul bisa dikarenakan adanya kebutuhan, keinginan maupun harapan yang tidak terpenuhi. Motivasi konsumen menjadi salah satu faktor yang membuat konsumen melakukan keputusan pembelian.

\section{SIMPULAN DAN SARAN}

\section{Simpulan}

Terdapat lima faktor yang menjadi pengaruh konsumen melakukan pembelian makanan melalui media sosial. Faktor pertama terdiri dari: tidak mau repot mencari barang (X6), memiliki layanan delivery (X15), tidak perlu mengantre (X11), dan praktis bisa diakses di mana saja (X5). Faktor kedua terdiri dari: tidak ada makanan di rumah (X12), cuaca yang buruk (X14), dan ingin update makanan terbaru (X16). Faktor ketiga yang terdiri dari: memiliki alternatif situs lain (X19) dan ingin mencoba produk baru (X10). Faktor keempat terdiri dari: harga yang terjangkau (X8), memiliki variasi barang yang banyak (X9), dan mempunyai promosi yang menarik (X7). Faktor kelima terdiri dari: visualisasi yang bagus (X13) dan jarak tempuh yang jauh (X17). Dari kelima faktor yang ada faktor yang paling dominan adalah faktor gaya hidup $(4,105)$ karena mempunyai hasil nilai eigen yang paling tinggi.

\section{Saran}

Para penjual makanan online harus lebih giat dalam melakukan marketing agar bisa menarik daya tarik konsumen. Seperti dengan memberikan promo-promo menarik saat ada event pada bulan tertentu (contoh: Christmas dan New Year). Memberikan hasil foto produk makanan yang bagus untuk menarik daya tarik bagi konsumen. Dan penjual makanan online harus lebih kreatif dalam menciptakan maupun menjual produk tersebut 


\section{DAFTAR PUSTAKA}

Adi, Rifqi N. 2013. Analisis Faktor Faktor yang Mempengaruhi Keputusan Pembelian dengan Sistem Pre-Order Secara Online. Jurnal Universitas Diponegoro, Semarang

Babin, Barry J., and Harris, Eric G. 2011. $C B^{2}$. South-Western Cengange Learning, USA

Balea, Judith. 2016. The Latest Stats in web and mobile in Indonesia (INFOGRAPHIC).

https://www.techinasia.com/indones ia-web-mobile-statistics-we-aresocial

Bela, Siti Maharani dan Anwar, Bayati. 2015. Dampak Globalisasi terhadap Nasionalisme. Karya tulis ilmiah MAN Kalabahi.

Bernhardt, Jay.M, Mays, Darren., dan Hall, Amanda.K. 2012. Social Marketing at The Right Place and Right Time with New Media. Journal of Social Marketing, Vol.2 Iss 2 pp. 135. Journal of Social Marketing

Boone, Louis.E dan Kurtz, David.L. 2013. Pengatar Bisnis Konteporer edisi 13 buku 1. Salemba Empat, Jakarta

Brogran, Chris. 2010. Social Media 101. John Wiley \& Sons Inc, New Jersey

Budi, Fajar Alam Setra. 2015. 7 Resep Rahasia Bisnis Kuliner. PT Elex Media Komputindo, Jakarta

Djumena, Erlangga. 2014. Ini Aturan yang Harus Dicermati Pebisnis Online. http://bisniskeuangan.kompas.com/r
ead/2014/08/22/203200426/Ini.Atur an.yang.Harus.Dicermati.Pebisnis.O nline

EMarketer. 2013. B2C Ecommerce Climbs Worldwide as Emerging Market Drive Sales Higher. https://www.emarketer.com/Article/ B2C-Ecommerce-ClimbsWorldwide-Emerging-MarketsDrive-Sales-Higher/1010004

Graves, Philips. 2015. Consumer.ology. PT Elex Media Komputindo, Jakarta

HarianTI. 2013. Ini Data Jumlah Pengguna Media Sosial di Indonesia. http://harianti.com/inidata-jumlah-pengguna-mediasosial-di-indonesia/

Hartono, Budi. 2014. Zaman Semakin Canggih, Gaya Hidup Berubah Pesat.

http://www.siperubahan.com/read/5 23/Zaman-semakin-canggih-gayahidup-berubah-pesat

Hidayat, Wicak. 2014. Pengguna Internet Indonesia Nomor Enam Dunia. https://kominfo.go.id/content/detail/ 4286/pengguna-internet-indonesianomor-enam-unia/0/sorotan_media

Kotler, Philip., Kartajaya, Hermawan., dan Setiawan, Iwan. 2010. Marketing 3.0: From Products to Customers to the Human Spirit. John Wiley \& Sons, Inc, New Jersey

Kotler, Philip dan Keller, Kevin Lane. 2012. Marketing Management. Pearson Education Limited, England 
Kustiawan, Robert dan Kuncoro, Irawan Adhi. 2013. Faktor - Faktor yang Mempengaruhi Keputusan Konsumen dalam Melakukan Pembelian Makanan Ringan secara Online. Jurnal Hospitality dan Manajemen Jasa Vol.1, No. 2

Masyhuri dan M, Zainuddin. 2011. Metodologi Penelitian Pendekatan Praktis dan Aplikatif, Bandung

Munajat, Wahyu. 2013. Info Seputar Dunia Internet dan Digital Marketing. http://www.infodigitalmarketing.com/2013/12/sejar ah-sosial-media-sejarah.html

Murwani, F. Danardana. 2009. Analisis Faktor dan Structural Equation Modeling. Buku Bahan Ajar tidak Diterbitkan. Program Pasca Sarjana Universitas Negeri Malang

Nory, Jones., Borgman, Richard., Ulusoy, Ebru. 2015. Impact of Social Media on Small Business. Journal of Small Business and Enterprise

Noviadhista, Ulwan Fakhri. 2016. Sudah 2016 BBM Masih Menjadi Aplikasi Chatting Favorit Orang Indonesia. http://www.techno.id/technews/sudah-2016-bbm-masih-jadiaplikasi-messenger-favorit-orangindonesia-160201v.html

Noviandari, Lina. 2015. Statistik Pengguna Internet dan Media Sosial Terbaru di Indonesia. https://id.techinasia.com/talk/statisti k-pengguna-internet-dan-mediasosial-terbaru-di-indonesia

Rahmat, Roir. 2014. Definisi Sosial Media. Jurnal UNG
Rebecca. 2016. Jenis - Jenis ECommerce. http://www.progresstech.co.id/blog/ jenis-e-commerce/

Ritonga, E. 2015. Tinjauan Umum Transaksi Jual Beli Media Internet. Jurnal Universitas Sumatra Utara, Sumatra Utara

Schiffman, Leon.G and Kanuk, Leslie Lazar. 2010. Consumer Behavior Global Edition Tenth Edition. Pearson Education Inc, New Jersey

Serfiani, Cita Yustisia., Purnomo, R.Serfiano dan Hariyani, Iswi. 2013. Buku Pintar Bisnis Online dan Transaksi Elektronik. PT Gramedia Pustaka Utama, Jakarta

Setyadi, Dyama Khazim. 2015. Memperluas Brand Awareness Netizen Indonesia Melalui Media Online. http://swa.co.id/swa/myarticle/memperluas-brandawareness-netizen-indonesiamelalui-media-online

Sholikah, Yuyun dan Muhammad, Edwar. 2015. Analisis Faktor yang Mempengaruhi Keputusan Pembelian Makanan Cepat Saji KFC Lamongan. Jurnal Universitas Negeri Surabaya, Surabaya

Sugiyono. 2015. Metode Penelitian Pendidikan Pendekatan Kuantitatif, Kualitatif dan $R \& D$. Alfabeta, Bandung

Supranto. 2010. Analisis Multivariat Arti dan Interpretasi. PT Rineka Cipta, Jakarta 
Versi Online: http://journal.ubm.ac.id/

Hasil Penelitian

Suryani, Tatik. 2013. Perilaku Konsumen di Era Internet Implikasinya Pada Strategi Pemasan. Graha Ilmu, Yogyakarta

Tirtana, Fanggi Ananta. 2013. Faktor Faktor yang Menjadi Pertimbangan Wisatawan Domestik Berkunjung di Objek Wisata Cangar Batu. Jurnal Universitas Negeri Malang, Malang

Trijono, Rachmat. 2015. Metodologi Penelitian Kuantitatif. Papas Sinar Sinanti, Jakarta
Jurnal Manajemen

Vol.13(2) : 85-191 Th. 2017

ISSN: 1907-0896

Turban, Efraim., King, David., Lee, Jae., Ting, Peng and Turban, Deborah. 2010. Electronic Commerce 2010. Pearson Education Inc, New Jersey

Usman, Hardius dan Sobari, Nurdin. 2013. Aplikasi Teknik Multivariate. Raja Grafindo Persada, Jakarta

Wawa. 2012. Keuntungan Menjadi

Pebisnis Online.

http://female.kompas.com/read/2012/01/1 2/14520378/Keuntungan.Menjadi.Pebisnis .Online 